\title{
Bacterial Contamination of Intraocular and Extraocular Fluids During Extracapsular Cataract Extraction
}

\author{
D. R. SHERWOOD, W. J. RICH, J. S JACOB, R. J. HART, Y. L. FAIRCHILD \\ Exeter
}

\begin{abstract}
Summary
Fluid aspirated from the anterior chamber and fluid drained from the conjunctival sac during 101 extracapsular cataract operations was examined for bacterial contamination. Bacteria were grown by enrichment culture from the conjunctival sac of 90 eyes and from the anterior chamber aspirate of 29 eyes. Conjunctival fluid, stained with fluorescein, was demonstrated to flow into the anterior chamber during the aspiration stage of extracapsular cataract extraction and during intraocular lens implantation. It is suggested that this fluid from the conjunctival sac, contaminated with bacteria, routinely enters the anterior chamber during extracapsular cataract extraction and is the likely source of some cases of post-operative endophthalmitis.
\end{abstract}

Post-operative bacterial endophthalmitis remains a catastrophic complication of cataract surgery. Efforts to prevent this type of infection have been hampered by lack of knowledge of the aetiology. Gram positive bacteria, in particular $S$. epidermidis have been most frequently isolated, ${ }^{1.2 .3 .4 .5}$ indeed, the first description of $S$. epidermidis endophthalmitis after cataract surgery was by Gifford in $1898 .{ }^{6}$ The mechanism of infection however, can usually only be postulated. In a minority of cases, specific surgical problems may allow entry of organisms into the eye following surgery. Leaking wounds, ${ }^{1}$ externalised vitreous strands ${ }^{7}$ and deep sutures ${ }^{8}$ have all been implicated as the cause of bacterial endophthalmitis. It seems likely that in the majority of cases the entry of bacteria occurs at the time of surgery. External contamination of irrigation fluids ${ }^{11}$ or the intraocular lens ${ }^{12}$ have been reported as causing clusters of cases. The infection is presumed to result from introduction of organisms from the patient's own eyelids or conjunctiva during the surgical procedure. ${ }^{11}$

This study was designed to assess:

(i) the degree of contamination of fluids bathing the eye during extracapsular cataract extraction

(ii) whether bacteria can be isolated from the anterior chamber during surgery

(iii) how fluid from the conjunctival fornix can be introduced into the eye during extracapsular cataract surgery and intraocular lens implantation.

\section{Materials and Methods}

One hundred and one consecutive patients undergoing routine uncomplicated extracapsular cataract extraction with posterior chamber lens implantation were included in the first stage of the study. None of the patients had 
external eye infections clinically and none received preoperative antibiotics topically or systemically. Pupils were dilated by topical cyclopentolate $1 \%$ and phenylephrine $2.5 \%$ drops instilled into the operated eye one hour pre-operatively. The skin of the eyelids and face was cleaned with Povidine Iodine $10 \%$. The immediate surgical area was draped with sterile drapes and an adhesive plastic incise drape, the edges of which were contoured round the eyelid edges to cover the lashes which were not cut. A sponge wick drain was placed in the lower fornix and drained into a sterile plastic bag attached to the drapes near the lateral canthus. This bag collected fluid from the operative site throughout the procedure and was retained for culture. A manual technique was used to aspirate the cortical remnants, using a Simcoe irrigationaspiration cannula, following delivery of the nucleus. The syringes containing the fluid aspirated were all retained for culture. Irrigation was provided from a gravity fed bottle of Hartmann's solution through standard sterilised plastic tubing.

A further ten patients undergoing routine extracapsular cataract extraction and posterior chamber lens implantation were included in the second stage. Following insertion of the irrigation aspiration cannula into the anterior chamber, through a limbal stepped section partially closed by two $10 / 0$ nylon sutures, $2 \%$ fluorescein was applied to the wound margins. Cortical remnants were then aspirated while the anterior chamber was observed for the presence of fluorescein. Antibiotic-steriod eyedrops (Betamethazone-Neomycin) were administered four times per day during the post-operative period.

\section{Bacteriological Methods}

The bags of conjunctival fluid and the syringes of anterior chamber aspirate were treated identically. Under aseptic technique, direct cultures were made from these fluids onto solid media and incubated at $37^{\circ} \mathrm{C}$ for 48 hours aerobically in an atmosphere of $7 \%$ $\mathrm{CO} 2$ and then anaerobically. Enrichment cultures were made by inoculating the remaining fluid and the wick into $100 \mathrm{ml}$ Fildes extract broth. If there was more than $25 \mathrm{ml}$ of fluid,
$25 \mathrm{ml}$ was inoculated into one bottle and the remainder into another. The bottles were incubated for 48 hours at $37^{\circ} \mathrm{C}$ and then subcultured onto solid media. The subcultures were incubated under similar conditions to the direct culture plates.

\section{Results}

\section{Bacteriology}

Conjunctival samples from 101 patients, and anterior chamber aspirate from 100 patients were cultured. Bacteria were cultured from the conjunctival drain samples by direct culture in 18 cases and by enrichment culture in 90 cases $(89 \%)$. Bacteria were cultured from anterior chamber aspirates in two cases by direct culture and by enrichment culture in twenty-nine cases $(29 \%)$. (Table I).

The positive cultures were caused by coagulase-negative staphylococci in 117 samples, Staphylococcus aureus in 15; Streptococcus viridans in five, diphtheroids in 15 and Moraxella $s p$. in one. Some patients had more than one type of organism isolated. (Table II). None of the organisms were multiply resistant to antibiotics.

\section{Contamination of anterior chamber fluid from conjunctival fluid}

Intermittent jets of fluorescein stained fluid were noted to enter the anterior chamber during aspiration in all ten patients during the irrigation aspiration procedure. (Figure). These were associated with active aspiration and were in some cases associated with slight anterior chamber shallowing. The site of entry was usually alongside the cannula but was also seen at other points of the wound. Fluorescein stained fluid was also seen to enter the anterior chamber during intraocular lens implantation.

\section{Discussion}

It has been shown that the conjunctiva of patients undergoing cataract surgery is heavily contaminated with bacteria. ${ }^{12,13,14} \mathrm{We}$ have confirmed this finding by demonstrating bacterial contamination of the fluids bathing the conjunctiva and operative site during extracapsular cataract extraction and posterior chamber lens implantation. We have also 
Table I Results of bacteriological culture

\begin{tabular}{|c|c|c|c|c|}
\hline & \multicolumn{2}{|c|}{$\begin{array}{l}\text { Conjunctival fluid } \\
\text { collected in bag }\end{array}$} & \multicolumn{2}{|c|}{$\begin{array}{l}\text { Anterior chamber fluid } \\
\text { aspirated in syringe }\end{array}$} \\
\hline & Positive & Negative & Positive & Negative \\
\hline Direct culture & 18 & 83 & 2 & 98 \\
\hline Enrichment culture & 90 & 11 & 29 & 71 \\
\hline
\end{tabular}

*1 specimen not received

Table II Positive cultures

\begin{tabular}{|c|c|c|c|c|c|c|c|c|}
\hline & \multicolumn{4}{|c|}{$\begin{array}{l}\text { Conjunctival fluid } \\
\text { collected in bag }(n=101)\end{array}$} & \multicolumn{4}{|c|}{$\begin{array}{l}\text { Anterior chamber } \\
\text { fluid aspirated in syringe }(n=100)\end{array}$} \\
\hline & Positive & 1 type & 2 types & 3 & Positive & 1 type & 2 types & 3 \\
\hline \multirow{2}{*}{$\begin{array}{l}\text { Direct culture } \\
\text { Enrichment } \\
\text { culture }\end{array}$} & 18 & 10 & 5 & 3 & 2 & 1 & 0 & 1 \\
\hline & 90 & 68 & 18 & 4 & 29 & 15 & 12 & 2 \\
\hline
\end{tabular}

${ }^{*} 1$ specimen not received.

found that a significant number of patients have potentially pathogenic organisms in their anterior chambers during the irrigation-aspiration phase of the procedure. Conjunctival fluid entered the anterior chamber during the aspiration phase in all patients observed during the second stage of the study. As we know this fluid to be contaminated with bacteria, this must be a cause of anterior chamber bacterial contamination. None of our patients developed clinical bacterial endophthalmitis suggesting that either the inoculum was not large enough or that the ocular environment was too hostile for multiplication of microorganisms or that the post-operative administration of antibiotic drops may also have been effective.

There are reports of continuing low grade inflammation after cataract surgery with intraocular lens implantation in some eyes as well as manifest endophthalmitis in others. Removal of the intraocular lens implant has led to resolution of the inflammation in some cases. ${ }^{15,16,17}$ Bacteria, some not normally considered pathogenic, ${ }^{18}$ have been cultured or detected in relationship to a nidus of inflammation in a dialing hole or on a lens loop. ${ }^{15,16}$ It is possible these bacteria enter the eye at the time of surgery and become semisequestrated in the vicinity of an intraocular lens and become responsible for recurrent low grade intraocular inflammation. We have demonstrated that contamination of the anterior

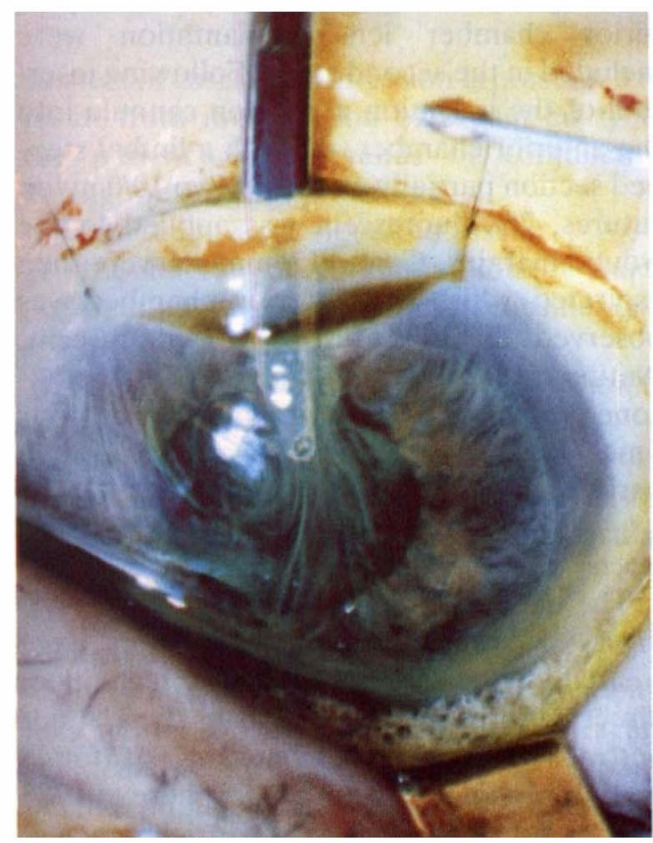

Fig. Fluorescein dye entering the anterior chamber during the irrigation-aspiration of cataract after a drop of fluorescein has been dropped onto the conjunctiva. 
chamber does occur regularly during extracapsular cataract surgery and it would seem reasonable to propose that this is a likely source of some cases of post-operative intraocular infection. Vafidis et al. ${ }^{14}$ have reported that PMMA lenses seem to have an affinity for bacterial contamination and found that $26 \%$ became contaminated by contact with conjunctiva and $15 \%$ of control lenses were contaminated by exposure to operating theatre air alone. It was postulated that the surface electrostatic charge of PMMA may be responsible. It is therefore possible that some cases of post-operative endophthalmitis are caused by bacteria brought into the eye on the implanted intraocular lens. In our study the aspirate from the anterior chamber was taken during the irrigation-aspiration stage of surgery and before the implantation of the lens. While bacteria from the edges of the wound may contaminate the irrigation cannula during entry into the eye we have demonstrated that in the surgical technique used fluid is readily and repeatedly aspirated into the anterior chamber from the conjunctiva which is known to be a source of bacteria.

It would seem prudent to attempt to minimise the number of bacteria entering the eye during surgery. It is obviously unwise to operate on eyes with frank conjunctivitis or blepharitis but efforts to reduce the normal flora have not been successful. ${ }^{12.13}$

The possible origin of the contaminating bacteria deserves further investigation with study of sources such as the surgeon's skin or theatre air and the effect of surface physical properties such as electrostatic charge on instruments and intraocular lenses. It may be possible greatly to reduce entry of conjunctival fluid into the anterior chamber either by making the wound more water-tight or by avoiding sub-atmospheric pressure in the anterior chamber during aspiration. The latter occurs when aspiration removes a greater volume from the anterior chamber than is replaced by the infusion. A high infusion volume flow such that at all times the gradient of flow is outwards from the anterior chamber could maintain the depth of the anterior chamber and prevent aspiration through the wound edges. Such high volume inflow however, is undesirable on grounds of the large diameter infusion cannula required and the turbulence in the anterior chamber produced by the high volume flow and the consequent danger of trauma to the corneal endothelium.

Both mechanised and manual methods of cortex aspiration aim to aspirate cortical remnants in a controlled fashion without causing anterior chamber shallowing or posterior capsule rupture. We have demonstrated the manual technique to cause entrance of conjunctival fluid into the anterior chamber and we suspect that mechanised methods will also result in bacterial contamination of the anterior chamber. Further work is obviously required to modify present methods of cortex aspiration during extracapsular cataract extraction to avoid bacterial contamination.

The authors would like to thank Mrs Cockram for secretarial help, and Miss Jones for photographic assistance.

\section{References}

1 Dreibe WT, Jr. Mandelbaum S, Forster RK. et al. Pseudophakic endophthalmitis; diagnosis and management.Ophthalmology 1986, 93: 442-8.

${ }^{2}$ Forster RK: Symposium: post-operative endophthalmitis. Aetiology and diagnosis of bacterial postoperative endophthalmitis. Ophthalmology 1978, 85: 320-6.

${ }^{3}$ Puliafito CA, Baker AS, Haaf J, Foster CS: Infectious endophthalmitis; review of 36 cases. Ophthalmology 1982, 89: 921-8.

${ }^{4}$ Rowsey JJ, Newson KL, Sexton DJ, Harms WK: Endophthalmitis: current approaches. Ophthalmology 1982, 89: 1055-65.

5 Bode DD, Gelender H, Forster RK: A retrospective view of endophthalmitis due to coagulase-negative staphylococci. Br J Ophthalmol 1985, 69: 915-9.

${ }^{6} \mathrm{Gifford} \mathrm{H}$ : Notes on ophthalmic bacteriology partly with reference to asepsis. Arch Ophthalmol 1898, 27: 616-64.

${ }^{7}$ Lindstrom RL and Doughman DJ: Bacterial endophthalmitis associated with vitreous wick. Ann. Ophthalmol 1979, 11: 1775-8.

${ }^{8}$ Confino $\mathrm{J}$ and Brown SI: Bacterial endophthalmitis associated with exposed monofilament sutures following corneal transplantations. $A m \quad J$ Ophthalmol. 1985, 99: 111-13.

${ }^{9}$ O'Day DM: Value of a centralised surveillance system during a national epidemic of endophthalmitis. Ophthalmology 1985, 92: 309-14.

${ }^{10}$ Pettit TH, Olson RJ, Foos RY, Martin WJ: Fungal endophthalmitis following intraocular lens implantation; a surgical epidemic. Arch Ophthalmol. 1980, 98: 1025-39.

"Forster RK, Zachery IG, Cottingham AJ, Norton 
EWD: Further observations on the Diagnosis, Cause and Treatment of Endophthalmitis. Am J Ophthalmol 1976, 81: 52-6.

12 Apt L, Isenberg SJ, Yoshimori R: Antimicrobial Preparation of the Eye for Surgery. J Hosp Infect. 1985, 6: 163-72.

${ }^{13}$ Isenberg S., Apt L., Yoshimori R: Chemical Preparation of the Eye in Ophthalmic Surgery. Arch Ophthalmol. 1983, 101: 761-3.

${ }^{14}$ Vafidis GC, Marsh RJ, Stacy AR: Bacterial Contamination of Intraocular lens Surgery. $\mathrm{Br} J$ Ophthalmol 1984, 68: 520-3.

15 Piest KL, Kincaid MC, Petz MR. et al: Localised
Endophthalmitis. A newly described cause of the so-called toxic lens syndrome. J Cat Refract Surg. 1987, 13: 498-509.

${ }^{16}$ Meisler DM, Palestine AG, Vastine DW. et al: Chronic Propinobacterial Endophthalmitis. Am J Ophthalmol 1986, 102: 733.

${ }^{17}$ Meisler DM, Zakov ZN, Bruner WE. et al: Endophthalmitis associated with sequested Propinobacteria acres. Am J Ophthalmol. 1987, 104: 428-9.

18 Schanzlin DJ, Goldberg DB, Brown SI: Staphylococcus Epidermis Endophthalmitis following Intraocular Lens Implantation. $\mathrm{Br} J$ Ophthalmol. 1980, 64: 684-6. 